\title{
A REPORT ABOUT INTIMATE PARTNER VIOLENCE IN SOUTHERN AND WESTERN RWANDA
}

\section{Immaculée Mukashema}

\begin{abstract}
The present paper reports on intimate partner violence (IPV) in 3 districts of Southern Province and Western Province in Rwanda. Qualitative data were obtained via 3 focus group discussions conducted at the headquarters of each district, and 10 individual interviews with key informants, community leaders who worked in the districts. The types of IPV discussed were physical, economic, sexual, and psychological harassment. Community leaders stated that the women in their communities had no hesitation in reporting economic abuse and physical violence, but noted that the women needed support from other people to report sexual violence, and generally did not report psychological harassment, perhaps because they accepted it as the norm. They also noted that men generally did not report IPV and that the main victims of IPV in all its forms were children and women. The community leaders suggested a number of measures to reduce IPV: empowering females so that they are financially independent; educating and sensitizing family members about their responsibilities and community leaders about laws and human rights; educating all community members about gender equality and IPV, including premarital instruction; increasing access to services; putting in place a law that protects free unions by giving them legal status after a period of cohabitation; setting up a specific institution to deal with IPV; improving both support to the victims and follow-up of reported cases, along with instituting punitive responses to deter potential new perpetrators.
\end{abstract}

Keywords: domestic violence, intimate partner violence, Rwanda

Acknowledgement: This research was conducted through the facilitation of the Rwandan Gender Monitoring Office's research initiative.

Immaculée Mukashema PhD is Associate Professor of Psychology in the Department of Social Sciences, School of Social, Political, and Administrative Sciences, College of Arts and Social Sciences, University of Rwanda. Avenue de l'Université, Butare, B.P. 117 Butare, Rwanda. Email: imukashema@yahoo.fr 
Intimate partner violence (IPV), also referred to as domestic violence, denotes abusive behavior by either partner or both partners in an intimate relationship (Shipway, 2004). It is defined by the American Centers for Disease Control and Prevention (2015) as:

a serious, preventable public health problem that affects millions of Americans.

The term "intimate partner violence" describes physical, sexual, or psychological harm by a current or former partner or spouse. This type of violence can occur among heterosexual or same-sex couples and does not require sexual intimacy.

IPV is a pervasive and devastating health and social problem that affects every population category in all nations (Bragg, 2003). Some cases end in the death of the victim by murder or suicide (Futures Without Violence, 2012; García-Moreno et al., 2013). The gravity of IPV's effects are recognized in the latest version of the Diagnostic and Statistical Manual of Mental Disorders, DSM-5, which recognizes marital conflict with violence as a new relational disorder, and thus identifies this behavior as pathological (American Psychiatric Association, 2013).

IPV violates the fundamental rights of its victims, and has been identified as a public health problem present in all societies (García-Moreno et al., 2013; Krug, Dahlberg, Mercy, Zwi, \& Lozano, 2002). For example, the United Nations Office on Drugs and Crime (2013) reported that, in Japan:

in subsequent surveys in 2005 and 2008, over 10 per cent of married women and approximately 3 per cent of married men reported that they experienced either "physical assault", "mental harassment or frightening threats", or "sexual coercion" by their spouse on many occasions. More than one in five married women and approximately 15 per cent of married men reported having experienced spousal abuse on one or two occasions. (p. 56)

In France, as reported by Molinié (2016), one woman dies every 3 days under the blows of her companion, and one man dies at his spouse's hand every 17.5 days ${ }^{1}$.

Rwanda has committed in the last two decades to dealing with IPV through legislation, policies, and strategies aimed at prevention and intervention. Attention is given to the full spectrum of IPV, including physical and economic violence, and also to the collateral damage inflicted on children: (a) a law "regarding matrimonial regimes, liberalities, and successions" (Republic of Rwanda, 1999); (b) a law determining the use and management of land (Republic of Rwanda, 2005); (c) a law on prevention and punishment of gender-based violence (Republic of Rwanda, 2008); (d) a law relating to the rights and protection of the child (Republic of Rwanda,

\footnotetext{
${ }^{1}$ Translated from French by the author.
} 
2012); (e) a national policy against gender-based violence (Ministry of Gender and Family Promotion [MIGEPROF], 2011a); (f) a national policy for family promotion (MIGEPROF, 2005); and (g) a national strategic plan for 2011-2016 (MIGEPROF, 2011b). Rwanda's Ministry of Gender and Family Promotion deals with issues relating to the promotion of gender equality and family welfare, including prevention of IPV. Article 185 of the Constitution of the Republic of Rwanda established the Gender Monitoring Office (GMO) as an independent Rwandan public institution with responsibility for monitoring and supervising compliance with governmental measures that support ensuring gender equality (Republic of Rwanda, 2003).

However, despite the Rwandan government's orientation and commitment to the prevention of IPV, it remains a challenging issue (MIGEPROF, 2011a). Data generated by a survey conducted in 2010 show that more than $50 \%$ of female respondents reported that they had experienced IPV, while $38 \%$ of male respondents reported having committed IPV (Sleght \& Kimonyo, 2010). As noted by Shipway (2004), conflict between spouses is often cited as a cause of IPV. In Rwanda, Mukashema and Sapsford (2013) have shown that IPV-related marital conflict rates are rising, as is the number of husbands who kill their wives and the number of wives who kill their husbands (MIGEPROF, 2011a). This rise in spousal homicides has been a cause of public alarm (Mukashema \& Sapsford, 2013).

Among the existing studies that provide information about the conditions associated with IPV in Rwanda, some focus on violence against women, connecting it specifically to HIV infection among women (e.g., Kayibanda, Bitera, \& Alary, 2012). Among other studies, Thomson, Bah, Rubanzana, \& Mutesa (2015), in examining the factors associated with physical or sexual IPV in Rwanda between 2005 and 2010, noted that in addition to the already occurring IPV-focused initiatives in the health and legal sectors, campaigns are needed to shift public perceptions towards deterrence; that is, towards ending IPV. These deterrence-focused campaigns are especially necessary given Umubyeyi, Persson, Mogren, \& Krantz's (2016) finding that even if legislative measures have been instituted to protect women from abuse, many Rwandan women do not benefit from those efforts.

Additional studies investigated IPV specific to pregnant women in Rwanda (e.g., Ntaganira et al., 2008) and IPV toward women and its relationship to the mental health of victims and perpetrators (Verduin, Engelhard, Rutayisire, Stronks, \& Scholte, 2012), while still others focused on the perspectives on IPV and marital conflict of psychologists, social workers, and medical professionals (e.g., Mukashema \& Sapsford, 2013). Despite the ongoing investigations of IPV, scholarly reports that provide an overview of IPV in Rwanda are few; examples include the annual reports produced by the Canadian Centre for Justice Statistics (Sinha, 2012, 2013), and studies that examine the impacts of existing legislation and policies focused on IPV prevention at the community level (e.g., Picon et al., 2017). With community impact in mind, the study described here investigates the awareness of IPV among community leaders and examines their perspectives and points of view about what further steps should be taken to deal with IPV in Rwanda. 
International Journal of Child, Youth and Family Studies (2017) 9(3): 68-99

\section{Methods}

\section{Participants}

The participants in the study who joined focus group discussions (FGDs) or provided individual interviews were local leaders and community-based workers who dealt with IPV, gender issues, and child protection and human rights affairs in their daily activities. The invitation to participate in the research was presented at the district level by the staff representative of the Ministry of Gender and Family Promotion who worked most closely with each prospective research participant; this approach helped by communicating official support for the study. Each focus group was composed of some of the following members at the district level: a representative of the Access to Justice Bureau; a representative of the National Women's Council; a community health worker; a staff member responsible for citizen registration; a land officer; a staff member in charge of good governance; people holding gender focal point positions; representatives of faith-based organizations and of the "guardian angels" 2 ; a representative of Haguruka [Stand Up], a local nongovernmental organization offering legal support to vulnerable children and women; and a representative of Pro-Femmes / Twese hamwe [Pro-Women Together], which is an umbrella organization working for the advancement of women, peace, and development in Rwanda. Data were collected in the Nyamasheke District of Western Province, and in the Nyaruguru and Huye Districts of Southern Province.

Individual interviews with key informants were conducted with representatives of stakeholders of the GMO and other public and civil society organizations. Each of the following institutions was represented in the interviews: the Access to Justice Bureau, the National Public Prosecution Authority, the National Police, the National Women's Council, the National Human Rights Commission, faith-based organizations, community-based organizations, the GMO, and the Ministry of Gender and Family Promotion.

Table 1 Number of Participants in FGDs and in Individual Interviews

\begin{tabular}{|c|c|c|c|c|}
\hline Place/District & Males in FGD & Females in FGD & $\begin{array}{l}\text { Males in } \\
\text { interviews }\end{array}$ & $\begin{array}{l}\text { Females in } \\
\text { interviews }\end{array}$ \\
\hline District A & 7 & 3 & 3 & 0 \\
\hline District B & 2 & 4 & 2 & 1 \\
\hline District C & 3 & 3 & 3 & 2 \\
\hline Total & 12 & 10 & 8 & 3 \\
\hline & \multicolumn{2}{|c|}{$\begin{array}{l}\text { Total number of participants in } \\
\text { FGDs: } 12+10=22\end{array}$} & \multicolumn{2}{|c|}{$\begin{array}{l}\text { Total number of participants in } \\
\text { individual interviews: } 8+3=1\end{array}$} \\
\hline
\end{tabular}

${ }^{2}$ In 2007 the Imbuto Foundation, chaired by the First Lady of Rwanda, Jeannette Kagame, initiated a network called Malayika Murinzi [Guardian Angels] in order to create a protective environment for children who do not have appropriate care by promoting adoption and foster care. 
International Journal of Child, Youth and Family Studies (2017) 9(3): 68-99

A total of 22 people including 12 males and 10 females participated in the three FGDs. Eleven people including eight males and three females participated in 10 individual interviews. In one interview, two people working in the same office for prevention of IPV chose to participate together, as they wanted to complement each other in giving their views.

Districts were represented by letters A (Nyamasheke), B (Nyaruguru), and C (Huye) in the data presentation and in the discussion. As Table 1 shows, the gender distribution of the participants included more males than females (12 males and 8 females in the FGDs; 8 males and 3 females for the individual interviews). This reflects the actual gender distribution at the time of data collection among those occupying the roles in the areas of interest of the research: local leaders and community-based workers who dealt with IPV, gender issues, child protection, and human rights affairs in their daily activities, as well as representatives of stakeholders of the GMO and other public and civil society organizations.

\section{Research Approach}

Data collection was conducted in May 2013. A moderator (the present author) and a notetaker (a research assistant) together conducted the three FGDs (one at the headquarters of each of the three districts) and the 10 individual interviews with key informants. The following questions were asked:

1. What is your understanding of intimate partner violence?

2. What are the different forms of intimate partner violence perpetrated in your district?

3. Are all cases of intimate partner violence reported?

4. What is the gender distribution of the victims? Who are the victims and perpetrators (men, women, or both)?

5. What strategies do you suggest should be put in place in order to combat intimate partner violence?

We developed interview guides relating to the research questions; these were used for both FGDs and individual interviews.

Ethical considerations of participation and confidentiality in research with human beings as participants were complied with. Participation was freely consented to and confidentiality was respected. Participants were not identifiable as research subjects in their workplaces because they participated in the study very much as part of their daily routine. From the outside a meeting with us looked like any other meeting, albeit somewhat longer so that we could cover the interview questions in our guide. To preserve confidentiality, participants' names were not mentioned in the collected data. FGDs and individual interviews were recorded with the permission of the participants. All the discussions were convivially conducted. 
International Journal of Child, Youth and Family Studies (2017) 9(3): 68-99

\section{Analysis Techniques}

The recoded data from the FGDs and individual interviews were transcribed and translated from Kinyarwanda into English. Thematic content analysis, a process for systematically examining text data using codes to facilitate retrieval of similar information across the data, was conducted (Miles \& Huberman, 1994; Rubin \& Rubin, 1995, 2005). First, the analysis considered the data from the FGDs separately from the data from the interviews. Throughout the analysis process, the location of the information given by the participants was recorded along with each of the identified themes and subthemes related to the research questions and objectives (Baribeau, 2009; L'Ecuyer, 1989, 1990; Duchesne \& Haegel, 2005). Codes were compiled into subcategories, then compared, and combined into broader categories. Second, the analysis of the FGDs yielded themes and ideas corresponding to each question; these were grouped with similar themes and ideas for the same question from the individual interviews for use in the report presentation and discussion.

\section{Results and Discussion}

The results from the FGDs and the interviews are presented and discussed under the following categories: understanding of IPV; forms of IPV; extent of reporting of cases; the gender distribution of both victims and perpetrators (men, women, or both); and suggested strategies to combat IPV. For each category, data from the FGDs are reported first, followed by data from interviews.

\section{Understanding of IPV}

In both FGDs and interviews, participants spoke about their understanding of IPV. For them, IPV was an act of violence conducted by one spouse against the other, an act that inflicted harm and deprived the victimized spouse of their human rights.

For me, intimate partner violence is when either spouse, husband or wife, is deprived of his or her rights by the other. (FGD in C, female)

I think it is any act done by someone to harm his or her partner. (FGD in A, male)

I understand this as an act of depriving one's partner of his or her rights, it is harming one's spouse. (FGD in B, male)

For me, it is violence committed against a partner, a man against his wife and vice versa. (interview in $\mathrm{A}$, male)

For me, it is a violence committed in violating the rights of a person against his intimate partner. (interview in $\mathrm{C}$, male)

It is a violation of the rights of the woman or of the man, but the definition must be consulted in accordance with the law. (interview in $\mathrm{C}$, female) 
International Journal of Child, Youth and Family Studies (2017) 9(3): 68-99

The participants' understanding of IPV fits with the WHO definition, which states that IPV "violates the fundamental rights of the victims" (García-Moreno et al., 2013; Krug et al., 2002).

\section{Forms of IPV}

Physical violence: Physical harm - beating and in other ways harming the body - of one partner by the other was identified by participants as a type of IPV present in Rwanda.

There are perpetrators who beat their victims, mainly the wives, and harm their body. Beating or harming the body is intimate partner violence. (FGD in B, male)

There are times when the husband beats his wife and hurts her so that she has to go to the hospital. (FGD in B, female)

To all the other types of violence cited discussed so far, I would add another type which is to harm the body, such as burning the body of one's spouse or other action to physically harm the body. (FGD in C, female)

Physical IPV is not specific to Rwanda; previous studies have included physical violence as a category of IPV in other countries as well (Ganley \& Schechter, 1996; Krug et al., 2002). Rwanda National Police released a report indicating that in 2016, out of all reported cases of battered intimate partners, 254 were women beaten by their husbands, while 52 were men beaten by their wives (IGIHE, 2017). In the two-year period from 2009 to 2010, 818 women were battered by their husbands and 188 men were battered by their wives (MIGEPROF, 2011a, 2011b). From 2012 to 2013, 25 men and 67 women were killed by their spouses ${ }^{3}$.

The numbers above show that battering of intimate partners seems to be decreasing. However, it is not known, and will not be easy to determine, whether this is a true decrease in battering or is only due to decreased reporting.

Economic violence: Participants identified several kinds of economic IPV, such as: nonagreement between intimate partners on the uses of economic goods, lack of access to family income by one of the intimate partners, and the exclusive management or use of shared property by one of the intimate partners (usually the man).

Spouses' disagreements on the uses of the economic goods they have in common often lead to constant harassment of one by the other. (FGD in A, male)

The two spouses can be both civil servants and earning wages, but the husband puts himself in a position of being the head of everything, to the point where the woman, even to be able to buy salt or sanitary napkins, has to beg for it from her

\footnotetext{
${ }^{3}$ http://www.newtimes.co.rw/section/article/2014-12-11/183917/
} 
International Journal of Child, Youth and Family Studies (2017) 9(3): 68-99

husband. The two partners are entitled to their wages, but the woman finds herself in a position of dependency. (FGD in $\mathrm{B}$, female)

Often women work very hard for the economic production, but the outcome of their efforts is not managed equitably by both men and women. The woman is not entitled to know the financial proceeds from the sale of their common goods.

Even to have access to the property to be mortgaged can be impossible even though that property was acquired by both of them. (FGD in B, female)

There are partners (mostly women) who do not have access to family income and property. Thus, the lack of access to family income and to property is an intimate partner violence. (interview in A, male)

Apart from the cases that we receive here, from information we have seen on television, we realize that in the countryside, women are the victims, they have no wage labor and the conflicts and violence taking place there are mainly related to economic affairs. (interview in $\mathrm{C}$, female)

The intimate partner violence is mainly based on economic aspects. Men are perpetrators against their wives and women are perpetrators against their husbands. About $99.9 \%$ of the complaints we receive in our daily activities are economic, especially land-related. (interview in B, male)

Previous studies agreed that issues related to economic exclusion, such as economic coercion of one partner by the other, are a type of IPV (Ganley \& Schechter, 1996; Bragg, 2003; García-Moreno et al., 2013). Systematic gender inequality in Africa is often reinforced by cultural traditions that place men in the role of head of household in charge of family finances and decisions (Bowman, 2003).

Killing of intimate partner: Participants in this study were aware that some people are killed by their intimate partners. Such a death seems to be understood as a catastrophic human behavior toward the intimate partner, going beyond the other physical aspects of IPV because it makes an end to the victim's life.

Physical violence can end in the murder of one of the intimate partners, the man killing the woman or the woman killing the husband. (FGD in A, male)

Death due to killing is an intimate partner violence; there are victims who are killed, murdered by their intimate partners, killers are mainly men. (FGD in C, male)

Murder of intimate partners is seen as a new phenomenon in Rwanda. According to a report released by the Rwanda National Police (IGIHE, 2017), 45 women and 19 men were killed by their spouses in 2016. In 2011, 121 women were murdered by their husbands, and 91 
men were murdered by their wives (MIGEPROF, 2011a, 2011b). These numbers appear to be not especially high given the Rwandan population of $12,085,195$, although one might argue that even a single such case is too many. The murder of one intimate partner by the other is a serious problem not just in Rwanda but around the world (Molinié, 2016; United Nations Office on Drugs and Crime, 2013).

The World Health Organization (WHO) identifies IPV as an epidemic — one that can be fatal. Thirty-eight percent of all murdered women were killed by their intimate partners (GarcíaMoreno et al., 2013). There are as yet no studies showing clearly the reasons for intimate partner killings in Rwanda. Rubanzana, Ntaganira, Freeman, and Hedt-Gauthier (2015) conducted a study of risk factors for homicide victimization in post-genocide Rwanda. They state that homicide victims tend to be relatively young and that the proportion of female victims is one of the highest in the world (Rubanzana et al., 2015). These authors argue that even in the context of residual effects from a mass genocide, homicide victimization risk factors are not unique to Rwanda. Thus, further research on the factors contributing to killings as one type of IPV in Rwanda would be of great interest.

Sexual violence and sexual forcing: Participants described several forms of sexual violence, mainly involving men who forced their female partners into unwanted sexual relations. The participants regarded this as a form of rape, with consequences such as injury to the sexual body areas of the victim. Some spoke of men who felt that their payment of a dowry to the wives' families justified their making use of their wives' bodies as and when they saw fit, even when the women were not physically or psychologically ready. In Rwanda, $22 \%$ of women in the reproductive age range reported ever experiencing sexual violence (National Institute of Statistics of Rwanda, Ministry of Health, and ICF International, 2012, p. xxiv).

When there is a disagreement on sexual practices between spouses, or forcing, generally by men, in unwanted sexual relations, rape, harm on the sexual body parts - that is intimate partner violence. (FGD in B, male)

There are spouses who do not communicate before intercourse, which ends up creating conflict between the spouses. The husband can tell his wife that as he gave the dowry to have it, he can dispose of his wife's body as and when he ... wants. ( FGD in A, male)

The husband may think that he is the chief or master of sexual relations with his wife, that he is the one who has the say over it, and that the woman must show submission whenever the husband feels like it. Whether the woman feels like it or not, her husband's wishes become an imperative to be followed and complied with. (FGD in B, female)

In my routine activities, I learn that there are some men who practise unusual and harmful sexual relations. This happens after those men have learned different 
International Journal of Child, Youth and Family Studies (2017) 9(3): 68-99

unusual sexual practices from outside, such as in prison, and want to practise what has been acquired on their wives. Negatively surprised, the victim comes to me telling that she wants to leave her partner because he has changed. (FGD in B, female)

There are participants who spoke of men going beyond the traditions and laws that placed them at the "head of the household" to thinking that they were the master in all aspects of life, including sexual relations.

Men go beyond the traditional law that gave to them the right to be called the [head of the household] and use it in forcing sexually their wives while these wives are not in normal conditions, either they are tired or sick and then they are not in a situation to agree to sexual relations. (interview in $\mathrm{A}$, male)

On this point of heading the household, it is encouraging to note that a new household management scheme was recently put in place in Rwanda. It specifies that spouses jointly provide management including moral and material support to the household, and also provide for its maintenance (Republic of Rwanda, 2016). As the public become familiar with this law, it may contribute to a change in the mindset of men with regard to the power relation between them and their intimate partners.

Psychological and spiritual violence: Participants identified different types of psychological IPV, including harassment, degrading language, putting the victim in a position of suffering, lack of care towards a partner, forcing adherence to a set of spiritual practices, obliging a female partner to wait without sleep for the male's return until late at night, irresponsibility in supporting wives in domestic activities, polygamy, and harassing of wives because of the sex of the baby she gives birth to. On the other side, however, some participants felt that women who indulge in activities such as watching movies rather than taking care of their husbands should be considered when discussing IPV.

Conjugal harassment may consist of degrading language or other action directed at the psychological suffering of the victim. There are victims of harassment who sleep outside the house, and the next day they go about their activities like everything is okay, nothing bad happened to them, they do not report officially, but only talk about it among them as ladies. (FGD in B, female)

There is absence of care toward men by women spending lot of time in the night watching series films on television while the husband is waiting for her in the bedroom very late in the night. (FGD in $\mathrm{C}$, male)

There are husbands who harass wives because of giving birth to only one sex. (FGD in B, male) 
International Journal of Child, Youth and Family Studies (2017) 9(3): 68-99

Can you imagine? I know an unfortunate case of intellectual spouses .... imagine that one is a lawyer who knows the laws, his wife is an economist. Do you know what they have for disagreement? This is because the woman bears only daughters! So, if an intellectual can say this how do you think that will be the situation for the people of the countryside, who are not intellectuals? ... I asked the following question to this man: Do you know that it is the man who gives the sex of the child, do not you know that at least through the books? He did not answer my question, he kept silent, now they are separated when they had three girls together! (FGD in $\mathrm{C}$, male)

We see intimate partner violence on faith where the husband forces his wife to be in his faith orientation. For example, two people may marry but have different religions. After marriage, the husband may forcibly require his wife to join him in his own belief church. (FGD in B, male)

There are men who, when they are outside the home during the night, oblige their wives to wait for them until they come. The wives are obliged by their husbands to wait for them and are not allowed to sleep before the husband comes even if it is very late in the night. To me that is a type of intimate partner violence.

(interview in $\mathrm{C}$, female)

There are irresponsible spouses, especially men, who do not take care of nor support their wives in domestic activities. (interview in A, male)

Not helping women with the household chores is a form of intimate partner violence. (interview in $\mathrm{B}$, male)

Polygamy is a great problem that ends sometimes in the abandonment of one spouse - the previous one - for another. Such a situation happens especially when a spouse wants to be with another partner who seems to be richer than the previous partner. (interview in A, male)

Psychological and spiritual violence are unhealthy, and amount to a public health problem. The WHO (Krug et al., 2002) includes psychological harm as a category of IPV.

\section{Extent of Reporting of Cases of IPV}

Reporting in terms of the gender of the victim of IPV: Women are said to report incidents of IPV much more often than men do. As one participant stated:

In terms of gender reporting, women are the main victims who report about intimate partner violence and the CNF [National Women's Council] helps in this. Men do not, maybe because of culture - they do not want to let it be known that 
they are victims of their partners. They do not want to be seen as victims of females. (FGD in A, female)

Reporting in terms of the type of IPV: IPV is not always reported as soon as it happens. Often, the victim herself is not able to report her own case; rather, the help of someone who can advocate for the victim is required. The psychological suffering of the victim is not disclosed unless it has resulted in physical consequences. Unlike psychological violence, economic violence is generally reported by the victims, and these are again mainly women.

Especially when it is a case of sexual intimate partner violence, female victims are the ones who report their cases. But note also that, even so, women do it only when the situation has already become intolerable. Intimate partner violence cases are not automatically reported; they are not reported as soon as they happen. (FGD in A, male)

When it comes to types of intimate partner violence, sexual violence is not systematically reported. When it is a sexual intimate partner violence, victims start by telling it to a confidante. Then this confidante may advise the victim to report to the $\mathrm{MAJ}^{4}$ or to police. The victim can't take the initiative of reporting his or her own case: this needs the help of CNF or of anyone who can help in doing advocacy for the victim about the violence faced. (FGD in A, male)

Intimate partner harassment, which may consist of degrading language or other action aimed at the psychological suffering of the victim, is not disclosed, it is not put out, it is not reported. This type of intimate partner violence becomes known only in the case of extreme physical consequences - of injury or death of the victim ... there are those who are victims of harassment who do not tell the authorities, there are some who are forced to sleep outside the house; the next day they go to their activities as if nothing had happened. (FGD in B, female)

The harassment between intimate partners that may be of the man against his wife or wife against her husband is not said - it is not reported. This is different from when the cases are related to economic violence. Women who are the main victims of economic violence now know that they can be assisted if, for example, the husband has unilaterally sold an economic good, the victim goes to the authority and denounces the husband's action and asks for advice on the procedure to follow for this violence to be resolved. (FGD in B, male)

I feel it is hard. I, who live in the countryside, I see that the situation is complicated for the woman who lives there in the countryside. The woman who

\footnotetext{
${ }^{4}$ MAJ means (in French) Maison d'Accès à la Justice [House of Access to Justice]; it is a service whereby people are freely assisted with legal services.
} 
lives in the countryside has a baby on her back, sometimes she is even pregnant, she went to the field with her husband if she is lucky enough to be accompanied by him for the work. Being back at a house, the husband asks the woman for food while they have both just arrived at home, having been working together in the field for agricultural activities... Even if the husband beats her, she must be silent, she must not denounce her husband, for fear of not being able to escape. She thinks that if her husband sends her away, she will not have a place to go, especially since even her own parents, especially her mother, informs her that this is how marital life works, that the difficult situation must be kept as it happens. So she lives in that situation ... the woman who lives in the countryside suffers, especially from economic violence. She works a lot for conjugal production, but her share of the product of her work is limited. (FGD in B, female)

Not all cases report themselves, many of the victims keep silent about intimate partner violence because the culture tells them that it is normal to live in such a situation of being violated by their husbands. Because of the influence of culture, many cases are not said, many keep silent because they say: "niko zubakwa [that's how homes work]"! (FGD in C, male)

Cases of intimate partner violence we are aware of in our hospital services are those which ended in physical violence, or in transmissible diseases; they are generally sent to us by the police. (interview in A, male)

Other factors inhibiting the reporting of IPV: Other factors that may keep a victim from reporting IPV are the psychosocial environment, intimidation of the victim, and the insufficient quality of the client care received from the people who handle reports of IPV, especially the lack of normal follow-up on the reported cases.

Reporting intimate partner violence is a very delicate situation. The administration is making efforts against intimate partner violence, but the result is not tangible. The victims are intimidated by the perpetrators who tell them that if they denounce them, they will kill them. Thus, the victims look at the consequences that they incur when denouncing the violence of which they are victims and choose to not report. (FGD in $\mathrm{C}$, male)

The way victims are helped may discourage other victims from telling about their case. There are people who receive the victims in bad ways which are not in accordance with the situation of the intimate partner violence. (FGD in C, female)

Reporting intimate partner violence also depends on how those who state their cases are accompanied, helped. I think there are problems here. I will give you an example. I once accompanied a woman who had been dangerously beaten by her intimate partner. When the victim arrived at the police station, a woman who was 
also at the police station at that time and who knew the victim said, "But why is this woman rushing to report the violence she is suffering from when she is not married legally with the man?" The police officer, who heard the reaction of that woman, took that opportunity to ask the victim, "Madam, are you not married legally?", and the victim replied that she was not. So the policeman said, "Well, be beaten to die, you whore!" ... Imagine the situation that had just been created, and that mother who had just been called a whore rather than being assisted on the acts of violence.... Fortunately the commander arrived at that moment and, observing the victim, he sympathized, and the situation became more or less relaxed... The way in which the victims are helped is problematic: Rwandans in general think that women can be beaten by their partners. (FGD in $\mathrm{C}$, female)

There are also times when repeated acts of violence take place and the local authority who receives repeated complaints from the same victim comes to have had enough, and can say to the victim, "But we help you and you do not stop your violence." This seems as if the situation of violence does not finally have definitive solutions and it is probably discouraging for the victim. (FGD in C, male)

We lack sometimes a model in the handling of intimate partner violence cases. Sometimes, you report the case of violence at the administrative sector level, but sometimes the person you're addressing yourself to does the same thing: he lives in the intimate partner violence situation. What help can that person bring? I do have a proposal: The counselors should be numerous because everyone is sick ... the reactions we see today shown on children, on men, on women ... They missed psychosociological assistance, they missed having someone to listen to them, and their situations degenerated. Permanent counseling is needed. (FGD in C, female)

Adequate support and follow up of reported cases and support to victims is an issue. That is what I observe and it grieves me much. Follow-up of cases: reported cases have no appropriate follow-up system. I do not know if this is because there are no consequences against the authority that does not take appropriate action on the case that is reported. I do not know whether this is due to the fact that he is not a model, or that he does not care about this case, or the fact that it may be due to the lack of knowledge about intimate partner violence. There are reported cases that are not treated, but are classified by the one who should follow it up.... There is no follow-up system that I know of. I am now in my third term as women's representative ... but I do not know any follow-up system. For example, one [official] can receive a case: he promises that this problem will be followed up and that stops there, nothing else is done after there. At one point after, we hear that a victim has just been killed, or a girl has just thrown her baby in the toilet; there are many reactions when cases of intimate partner violence are not followed 
up. The woman we visited at the hospital who had been burnt by her husband by pouring a pot of potatoes on her face, she was burned on her face, on her breasts, but I tell you the truth, it has not had any continuation. (FGD in $\mathrm{C}$, female)

I learned that he asked for forgiveness and that he received it. (FGD in $\mathrm{C}$, female)

I too learned that he was forgiven to the police and that is all. This kind of person - a professional who interceded for forgiveness when he was the one who would have punished the crime - should be answering this, he should be accountable to this. (FGD in C, female)

Several factors influence whether an IPV incident will be reported. The gender of the victim plays a role. Most of the victims who report IPV are female; men tend not to report, perhaps due to the influence of the culture: men may deny being victims to avoid being known as the victims of females. This is consistent with the findings of Umubyeyi, Mogren, Ntaganira, and Krantz (2014), who, with regard to men's lower reporting, stated that men's denial of incidents could be explained by the gender role pattern.

Sexual and economic violence are the types of IPV most likely to be reported. Sexual abuse by a partner is more often reported by female than by male victims, but the reporting is not automatic, nor does it usually take place immediately. Instead, the female victims tend to keep silent until the situation has become more and more catastrophic and reaches a breaking point. They take rarely the initiative on their own to report, but need support from other people, especially from organizations dedicated to women's development such as CNF (Conseil National des Femmes [National Council of Women]) and from any person in a position to advocate for the victim. Indeed, consistent with the present findings, it has been reported that only $42 \%$ of women who have ever experienced physical or sexual violence sought help from either formal or informal sources; the majority of women preferred informal sources of help, such as family, in-laws, friends, or neighbors (Umubyeyi et al., 2016). However, while the present study found that in order for female victims of IPV to report they need the assistance and support of others, Thomson et al. (2015), in a study on correlates of IPV against women during a time of rapid social transition in Rwanda, analyzed the 2005 and 2010 Rwanda Demographic and Health Surveys and found that Rwanda has one of the highest self-reported rates of IPV against women worldwide, and that multiple forms of current or past violence are reported by the same women. This suggests a need for further studies on the conditions leading to cases of IPV being reported.

The victims of economic violence are usually female; there is less reluctance to report this type of IPV. Intimate partner harassment, on the other hand, is not generally reported to authorities. This type of IPV is usually recognized only when it leads to extreme physical consequences - the injury or death of the victim. Cultural influences play an important part in the underreporting of cases, especially in the countryside, where women are less educated. 
Female victims are exhorted to live with the IPV they suffer from because, as the saying goes, "niko zubakwa [that is how homes work]". For male victims, it is not culturally easy to accept and reveal that one is the victim of a female intimate partner.

Other factors also play a role in discouraging the reporting of IPV. These relate to the psychosocial environment, and intimidation of the victims by the perpetrators. If the perpetrators tell the victims that if they denounce them, they will be killed, the victims will probably choose not to report. This is consistent with the statement that women feared revealing abuse to anyone, either within or outside the family, as this would bring shame to the family and worsen their overall life situation (Umubyeyi et al., 2016). Umubyeyi and colleagues recommended that a study be carried out on gaps in legislation aimed at supporting abused women; they also suggested the need for a study on gaps in the involvement of health care professionals in supporting abused women (2016). Untrained or insufficiently trained staff, or staff whose moral values negatively impact their relationships with the victims, will lead to unsatisfactory client care and will handicap the reporting of IPV cases. It is of great importance that professionals who deal with IPV cases should receive the right training to develop the needed skills. Previous authors have made similar recommendations. For example, in the medical aspect of IPV, Umubyeyi et al. (2016) recommended that health care professionals should be better prepared through further education, and guidelines on how to handle such cases.

With regard to reported cases of IPV, Thomson et al. (2015) conducted an analysis of the 2005 and 2010 demographic and health surveys. They concluded that there had been a doubling in self-reported violence between 2005 and 2010, and that it coincided with major political and social gains in Rwanda. However, they also recommended that additional research be conducted to tease out to what extent-increased self-reports of IPV are due to increased IPV incidence rather than greater empowerment by women to report violence. They also stated that research is needed to evaluate the effectiveness of IPV interventions such as police station gender desks and district hospital Isange [Feel Welcome] One Stop Centers ${ }^{5}$ in reducing the incidence of IPV (Thomson et al., 2015). Participants suggested that good follow-up of reported cases is necessary in order to avoid extreme consequences, such as death. There is a need to expand the number of locations where justice services can be accessed, so that in each two or three administrative sectors there are justice services to support victims in the local area. There is a need for psychologists at police offices and for a multidisciplinary team to deal with IPV. As Bragg (2003) suggested, this could be beneficial in such areas as crisis counseling and interventions, support groups, medical and mental health referrals, legal advocacy, vocational counseling, and children's services.

\footnotetext{
${ }^{5}$ The Isange One Stop Center is a multisectoral and interdisciplinary program aimed at providing psychosocial, medical, police, and legal services to adult and child survivors of gender-based violence and child abuse in Rwanda. The first one was created in July 2009 at Kacyiru Police Hospital in Kigali. Currently, there are 16 Isange centers at established district hospitals (http://www.newtimes.co.rw/section/article/2016-01-06/195864/).
} 
International Journal of Child, Youth and Family Studies (2017) 9(3): 68-99

\section{The Status and Gender Distribution of Victims and Perpetrators of IPV}

Participants felt that children were incontestably victims of IPV. When asked to rank the main victims of IPV by importance, they put children first, women second, and men third. This is apparent from the FGD and interview data, but also from the energy that was put into talking about the issue of victims of IPV. Participants unanimously reported that the victims of IPV include both female and male partners, and that the children of violent intimate partners are collateral victims. When discussing "who are the victims" of IPV, both nonverbal behaviors and the tone of the conversation clearly showed the insistence of the participants that children and women are the main victims of IPV, with men in third place.

Children are the main victims of intimate partner violence. In terms of gender of the victims of intimate partner violence, both men and women are victims. (FGD in A, male)

When I look at it, I realize that children are the first victims. A child who lives in a marital home where there is a IVP, he gets hurt psychologically, fails to be properly educated by his parents. Then he will not be able to properly follow his lessons at school. He grows up in an environment of conflict.... When he sees that his parents are still fighting, he may think that when the day comes when he will have his own marital home, the situation will be the same, which puts him in a situation of [psychological discomfort]. (FGD in C, female)

To me, victims of intimate partner violence are women and children. Even if the female was the perpetrator of the intimate partner violence, her nature as a female means that she also became the victim of the situation she created herself. (FGD in A, female)

To me, whether the intimate partner violence is perpetrated by men or by women, the victims are children and women; if I try to make a kind of proportion, I can say that $90 \%$ of victims are women and children and $1 \%$ or $2 \%$ are men victims of intimate partner violence. (FGD in $\mathrm{B}$, male)

The victims of intimate partner violence are firstly children, women secondly, and men thirdly. But this depends on the perpetrator of the intimate partner violence. (FGD in A, male)

Here in our district, if I compare it with other districts I've worked in, I realize that it all depends on the district.... I have tangible cases where both sides are undergoing intimate partner violence. Intimate partner violence is not committed against women only, men also come and tell us that they are the victims of intimate partner violence by their wives. Women give a mistaken interpretation of gender equality: she now knows that she is the equal of man. As the man 
International Journal of Child, Youth and Family Studies (2017) 9(3): 68-99

approaches her, she calls the police saying her husband has just beat her and the rumors are circulating as well.... Today, there are men who have made the decision to leave the domestic home leaving their wives behind them.... The reference I can give you is that of about four requests for divorce, one can be a man. (FGD in B, female)

Women are the main victims. Yes, there are some cases of men who are victims, but the majority of victims of intimate partner violence are women, and most of the perpetrators are men. (interview in A, male)

Most of the victims we receive in our services are female; only about $1 \%$ are male. (interview in $\mathrm{B}$, female)

Most of the time, the victims of intimate partner violence are women. The reason for this is that, generally speaking, in the Rwandan mentality, the husband is the head of all... But with regard to the new law of the family on the two spouses as chiefs.... He may want to use conjugal economic assets as he wishes, unbeknownst to the woman. So if the woman presents resistance to her husband, she ends up being violated by him. It is in this way that the violence begins. (interview in B, male)

But there are also women who want to seize and use only matrimonial goods, under the pretext that the law protects them. (interview in A, male)

Women and girls are the main victims of IPV, and children are the main victims of the consequences of intimate partner violence. We regularly face these types of violence. Even when we do interventions with people who are facing intimate partner violence, we want to help mainly their children. (interview in $\mathrm{C}$, female)

Children and women are said to be the main victims of IPV. Men are said to be the usual perpetrators even if they also are sometimes victims. This finding about the gender of the victims and perpetrators of IPV is consistent with Umubyeyi and colleagues' (2014) study conducted in rural and urban areas of Rwanda's Southern Province. The authors found that both men and women were exposed to IPV, although men to a considerably lesser extent than women. IPV exposure, in the form of repeated acts of physical, sexual, and psychological violence, was commonly faced by women, while men reported only single incidents of violence.

In sub-Saharan Africa, women are more exposed to IPV than men (Were et al., 2011). Men report less exposure to physical and sexual violence while psychological violence exposure is more evenly distributed, irrespective of the time span under investigation - for example, the past year, or a lifetime (see, e.g., Nybergh, Taft, \& Krantz, 2012). Some researchers have suggested that female victims are also often perpetrators of violence and that the victim and perpetrator roles can be played by both men and women (see, e.g., Bélanger, Mathieu, \& 
International Journal of Child, Youth and Family Studies (2017) 9(3): 68-99

Brisebois, 2013). While it is true that IPV is perpetrated by both women and men, the majority of cases worldwide are perpetrated by males against their female partners (García-Moreno et al., 2013).

\section{Proposed Strategies against IPV: Effective Preventive Measures}

Participants suggested a number of measures as effective preventive and responsive actions for IPV. These include fighting against poverty, educating and sensitizing family members about their responsibilities and community leaders about laws and human rights, involving the churches in the fight against IPV by promoting mutual respect, training and educating people about gender equality and IPV, increasing the access to social services, reducing the distance to access help in cases of IPV, and improving telephone and other

communications facilities. They also proposed putting in place a law discouraging and protecting free unions, the creation of a specific institution in charge of IPV, premarital education, adequate follow-up of reported cases and supporting of victims, and the punitive response.

\section{Fighting against poverty}

A woman who does not make economic inputs to the home, even if she is in charge of rural field work and other domestic activities, is not given value in the home. (FGD in C, female)

Women do not yet have the same economic resources as men... They have begun to make economic contributions to their homes, but they have not yet reached the same level as men. (FGD in C, female)

We see many people living in poverty. So when the wife asks her husband for something while the husband does not have the financial means to satisfy his wife's request, both spouses begin to denigrate each other. I think fighting poverty would be a solution to the intimate partner violence related to the impossibility of meeting the economic needs. (interview in $\mathrm{C}$, male)

In their study, Umubyeyi et al. (2014) also suggested that income generating activities and access to financial credit would contribute to women's empowerment.

Educating and sensitizing families members about their responsibilities and community leaders about laws and human rights

Educating men and women so that everyone knows about their conjugal duties, ... the man has the responsibility to produce for and protect the home... The solution is to try to educate.... Our contribution as a church is to educate. At least my son understands who the woman is, and who the man is. This is to avoid that, as we have seen that children are the first victims of intimate partner violence, 
that if they see their father beating their mothers, these children do not think that this is how it should be. (FGD in C, male)

It is important that the laws are explained to the people who are the beneficiaries. The laws are potentially good, they come to regulate marital and family problems, but people do not have the same interpretations regarding the laws. Men and women, and even children, must have the same understanding and interpretations of the law governing the family. The laws are not explained in ordinary language, laws are not sufficiently disseminated.... You see that there are even intellectuals who act badly, more than those who are not educated.... When the laws are not explained to the population, this creates difficulties.... It is said that a law has gone out in the Gazette, ... but how many read the Gazette? Laws are good, but lack of knowledge about them by beneficiaries is a problem. (FGD in C, female)

I agree with the same point, it is urgent to educate and explain the laws on the family.... To speak on radio and television is not enough.... Even among those who listen to the radio or watch television, ... many are interested in other shows like football. (FGD in C, male)

To educate people on different contents of laws for human protection, at the village level. (FGD in A, male)

There is a need for sensitization of local government ... and the population on human rights. (FGD in $\mathrm{B}$, male)

It is important to educate people about their rights. Someone may be confronted with intimate partner violence and believe that their torturer has the right to do so. It is important to know their rights and to know how to seek help in the case of intimate partner violence in order to claim rights when they are baffled. (interview in $\mathrm{B}$, male)

We must continue to raise awareness so that people know the rights of others. This is because, for example, there are men who believe that all rights belong to them, forgetting that women have rights also. (interview in $\mathrm{C}$, male)

It is necessary to educate the population on the right way to live. They should also be made aware of the types of intimate partner violence. A woman can publicly denigrate her husband and the husband does not know that this is a form of intimate partner violence. This affects the harmony of their life. (interview in A, male)

Since they have not learned this at school, it is necessary that local authorities should be educated about intimate partner violence. In turn, these local authorities 
International Journal of Child, Youth and Family Studies (2017) 9(3): 68-99

have to educate, to sensitize the population about intimate partner violence. (interview in A, male)

Educational awareness on gender equality and human rights issues would contribute to women's empowerment (Umubyeyi et al., 2014).

Involving the churches in the fight against IPV by promoting mutual respect

Churches should help people to change and family members to be patient with each other. (FGD in C, male)

In addition to the existing administrative institutions and the specific body dealing specifically with intimate partner violence, churches would help to educate the faithful on the fact that no one among intimate partners is an angel. (interview in C, female)

\section{Training and educating people about gender equality and IPV}

The gender concept needs to be well understood: men think that gender [equality] is only to the advantage of women and causes women not to respect those men. Men say that gender gives power to women. (FGD in B, male)

Increasing access to social services, reducing the distance to access help in cases of IPV, and upgrading telelphone and other communications facilities

To increase MAJ so that each two or three administrative sectors should have a MAJ service near the population. (FGD in A, male)

People travel long distances to reach police stations and MAJ services. For example, you see we are now at 10 a.m., but it is possible that someone who is coming here may be still on his way to here. It would be good to make available at least more than one bureau of MAJ, at least one MAJ bureau for two administrative sectors. However, it is necessary to sensitize the population about the opportunity they have ... to use the calling way [a free telephone call] to police stations in order to report cases and get assistance. (interview in A, male)

\section{Proposing a law both discouraging and protecting free unions}

There should be a law discouraging and protecting free relational unions. For people who live without being legally married, there is a form of instability that takes place in them and which influences their lives. This instability makes neither partner feel responsible for their household. Why cannot we decide by law that if a couple who are not legally married has spent a certain amount of time 
together, the household will be legally recognized as a home. We need to protect these families... This is a problem we often hear about ... here. Every year we officially legalize illegal relationships, there is nothing preventing these types of disorderly relationships. Thus, if a man has decided to live with a girl, thinking that this is only a way for him to acquire the satisfaction of his sexual enjoyments, he has to feel engaged in responsibilities, that it will not be easy to get rid of her should he wish it. And for the girl, she will have to understand that if she engages in this type of relationship, it involves responsibilities, and that if she has spent a certain time with that man, he will be her legal husband. (FGD in C, female)

I was in an administrative sector of our district. I had discussions with people in charge of the civil registry, community police, and so on. I asked them the following question: A young man and a girl decide to live together as husband and wife, how will you behave in this situation as a responsible action? ... I addressed this question to about four people randomly chosen in the assembly and their answers were the same: we will try to hunt this strange girl ... so understand that that girl becomes a victim of violence.... I added another question: and if she ever became pregnant in the time she was with that man, what will become of the child she carries... All answered that he will be a street child ... and you see, those are leaders ... there were pastors, executive secretaries of the administrative cells, development officers at the level of the administrative unit ... and we have conducted such discussions in all the administrative sectors ... by bringing together all these categories of people.... It is a problem, they said ... but who can be sure that this pregnancy is not due to someone other than this young man? (FGD in $\mathrm{C}$, female)

\section{Proposing a specific institution to address IPV}

It would be helpful to set up a specific institution in charge of intimate partner violence so that it may be managed well, because it seems that in some existing institutions, intimate partner violence is given less importance ... and this may be because there are more important problems for those institutions to handle. (interview in $\mathrm{C}$, female)

What I can propose is that there will be a specific body in charge of awareness and prevention of intimate partner violence. There should also be a specific law to punish intimate partner violence, for the population to become seriously aware of the problem of intimate partner violence. There should be a specific focus on intimate partner violence as there is, for example, a specific body for cases about trade. (interview in $\mathrm{B}$, male) 
Undoubtedly, one can say that the problems [of intimate partner violence] do not resolve... It is not easy to know exactly where is the blocking ... many of them remain in suspense. At least, you never see someone saying that his intimate partner violence problems have found solutions at $100 \% \ldots$.. We think it would require a specific body dedicated to intimate partner violence and marital problems. I think that if intimate partner violence has not been solved as it is wished and wanted, maybe it is because the normal channels [of justice], which have to cope with varied problems of varied weights, can be overwhelmed if there are [many domestic violence cases] in addition to robbery and other serious crimes. When this happens, those other serious crimes receive much more attention; household crimes receive little importance if [the authorities] are involved in these other cases of crimes of particular gravity. This is the reason why we say that it could be fruitful if there was a specific body for solving conjugal problems. Existing institutions deal with many other crucial, important issues. When intimate partner violence cases arrive at police stations, in existing courts, and there are serious cases other than intimate partner violence, they [IPV cases] receive little attention beyond what is considered important in their [the courts] particular context. Just as there was a particular body that came to solve specific cases, the Gacaca [community justice court] came to solve specific problems of genocide and it was effective according to what was expected from them. A task force to deal with these domestic problems at the sector or district level, this would depend on the institutionalization, discussions focused on these problems; I think this may have good results, better than we see today. (interview in $\mathrm{C}$, female)

\section{Premarital education}

What I can add on the topics of community education, is that there should be specific themes for those who are getting ready to get married ... so that they understand the concept [of] gender ... so that everybody marries knowing what awaits him in married life and what he will have to do in order to avoid annoying the other, his spouse. (FGD in C, female)

Premarital education should be conducted early and many times. There is a need for family counselors and for setting up a good methodology to improve education on family dynamics - living together. (interview in $\mathrm{C}$, male)

\section{Adequate follow up of reported cases and supporting of victims}

It would be helpful to follow up reported cases to avoid extreme consequences, such as death. (interview in B, male) 
International Journal of Child, Youth and Family Studies (2017) 9(3): 68-99

There is a need for a psychologist at police stations, and there is a need for a multidisciplinary team that can make what is called a One Stop Center. (interview in $\mathrm{C}$, female)

\section{Punitive response}

It would be important to consider intimate partner violence as a criminal act to be punished before the population in a public place. (FGD in $\mathrm{B}$, male)

What I can add is that all intimate partner violence should be considered as criminal cases. We support the forgiveness that can be given by a victim of intimate partner violence, but there are no lessons that this can give to others.... See for example that man overturning a boiling pot of sweet potatoes on his wife and sometime later, he said to his wife, "Pardon me, my wife, you know that we have children together" ... and the victim forgives.... In these conditions, another man will do the same thing because he will tell himself that women are like that, they are violated and they forgive. The perpetrator must be punished and the victim must be protected. (FGD in C, male)

I, too, would like to argue that intimate partner violence should be considered as criminal. The prosecution must recognize the value of forgiveness, but he should also recognize that forgiveness is not enough in cases of intimate partner violence, and that punishment is necessary. Intimate partner violence must be seen as criminal and punished as such. (FGD in C, male)

\section{Discussion of the Proposed Strategies}

One available preventive measure is that of addressing the problem of poverty. Although Rwanda has embarked on a policy of empowering women, they have not yet reached the same status as men. Thus some are still dependent on men financially. When women are obliged to beg money from their male partners, this may lead to underestimating the value of women as human beings. The value of women is sometimes estimated in terms of the income they can bring into the household.

Each intimate partner needs to be educated about his or her responsibilities in the relationship. It is important that children have good role models so that they will behave properly when they have their own households. The role of family education in preventing IPV is crucial.

The laws, especially the laws regulating the family, need to be explained to those who will benefit from them. Although a law may have the potential to do good, unless people at all levels of instruction and all degrees of social status know and understand the law, that potential will not be realized. Local leaders in particular, and the population in general, need to become 
International Journal of Child, Youth and Family Studies (2017) 9(3): 68-99

knowledgeable about IPV, human rights, and what steps to take when human rights are violated by IPV.

The concept of gender needs to be well explained, because there are men and women who misunderstand it. The misunderstanding of the gender concept can lead to inappropriate behaviors in a relationship between intimate partners. Rwandan psycho-socio-medical professionals have emphasized the importance of making the concept of gender well understood in order to prevent conflict and violence linked to misunderstanding of gender by men and by women (Mukashema \& Sapsford, 2013). The need for education and sensitization as a measure to prevent family conflict leading to violence was also noted (Mukashema \& Sapsford, 2013).

Religious institutions can help to prevent IPV by promoting attitudinal change and mutual patience among family members. Advocacy efforts such as public awareness campaigns, collaborating with community services providers, and efforts to secure safety for victims and their children (Bragg, 2003) can help raise awareness about IPV. To succeed, strategies to reduce partner violence need the combined commitment of all actors, such as government and civil society (Abramsky et al., 2011).

The helping services in cases of IPV, such as MAJ and police stations, should be as nearby and accessible to the population as possible. Rwanda has set up a communications strategy that allows IPV victims to report offenders with a free telephone call. Putting in place a law discouraging and protecting free relational unions, by giving them legal recognition after a period of cohabitation, would be good for the prevention of IPV against women and would especially benefit the children of those unions. Formal marriage needs to be emphasized as a protective factor against IPV (Abramsky et al., 2011).

The participants suggested that a specific institution in charge of IPV should be created. They felt that IPV is not given enough importance, perhaps because institutions that are handling IPV also handle other serious issues to which they give more weight. An institution focusing only on issues of IPV and domestic violence could reduce this problem. These important suggestions come at a time when there is an effort to address IPV already underway in Rwanda, with a number of laws formulated to this end. For example, in 2008, a law regarding the prevention and punishment of gender-based violence was put in place. In 2009, a One Stop Center project offering free, integrated medical, psychosocial, and legal services to victims of IPV and child abuse was created. Almost all police stations now staff a gender desk with trained, usually female, personnel in order to help victims of IPV and other forms of domestic violence. The need for such measures indicates that IPV in Rwanda is an alarming issue. Indeed, it impacts negatively on the family, the smallest social unit and the foundation of a normal and harmonious nation.

Participants emphasized the importance of sufficient time for premarital education for people wishing to get married. Premarital education was also suggested in a previous study as a 
method of preventing marital conflict in Rwanda (Mukashema \& Sapsford, 2013). For the purpose of premarital education, there is a need for family counselors who would set up a methodology for education about family dynamics (living together) in Rwanda. This premarital and family education should protect the children from IPV. Abramsky et al. (2011) suggested that early experiences of abuse for children are a strong risk factor for IPV in adulthood. Protecting and supporting victims and their children is a necessary responsive action to IPV (Schechter, 2000).

All reported cases of IPV should be followed up to avoid extreme consequences, including death. A multidisciplinary team, consisting of staff well trained in handling IPV, should be in charge of the cases to ensure good and comprehensive client care and adequate support to victims. While the Rwandan health and legal sectors have multiple initiatives to support victims, additional campaigns may be needed to shift public perception and reduce perpetration of IPV (Thomson et al., 2015).

Even in recognizing the value of forgiveness in relationships, punishing IPV is needed as an example to other potential perpetrators. Participants believed that public punishment would discourage domestic violence. Suggested responsive actions to IPV from previous studies included improving the legal and criminal justice response (e.g., Schechter, 2000), accountability for perpetrators of IPV through societal and criminal sanctions, and systematic changes to combat IPV and to promote victims' rights (Bragg, 2003). Women who survive IPV feel more empowered to report by the protection provided by the laws, and, as a result, an increase in the number of arrests for non-lethal spousal violence has occurred (United Nations Office on Drugs and Crime, 2013).

\section{Conclusion}

IPV was understood by the participants in this study as an act characterized by the deprivation of spouses' rights and involving violence, physical or otherwise, by one spouse against the other. One noted, however, that the definition given by law must also be kept in mind. Physical IPV may consist of beating and harming the body of the victim, which can end in the death of the victim. The identified features of economic IPV are non-agreement between intimate partners on the uses of their economic goods; lack of access to family income by the victim, who is generally female; and the selfishness of the perpetrator in the management and the use of their common property. Sexual IPV consists mainly of unwanted sexual relations perpetrated by men. Some men think that the payment of a dowry to the wife's family confers on them the right to control their female intimate partners and even abuse them. Some also cling to the traditional male role as head of the family, with the right to dictate practices in the area of sexual relations. Psychological IPV includes harassment, degrading language, failing to take care of one's partner, imposing spiritual adherence, and the persecution of wives according to the sex 
of their babies, as well as irresponsibility in supporting the victims (generally the wives) in domestic activities.

Participants noted that the victims who report IPV are most often women. However, sexual violence frequently goes unreported. Victims may initially keep silent, then make a report when the situation has become unbearable. Female victims of sexual violence generally need support from other people before they report. Economic violence is the form of IPV most readily reported by its victims, who are generally female. Harassment, on the other hand, is not generally reported to authorities, even though it may lead to a degenerating situation with extreme physical consequences including injury to or the death of the victim. To some extent, failure to report cases of IPV is influenced by culture, especially in the countryside, where women are less educated. They may be told by elders, especially their family members, that being violated is not unusual for a wife, and that it is simply how homes work (niko zubakwa). Men generally do not report IPV. This is probably linked to traditional cultural influences that lead men to deny being the victim of a female intimate partner. The Rwandan government is making efforts against IPV, especially in raising awareness among victims of the benefit of reporting IPV, but the results are not yet tangible. Some factors that explain the underreporting of IPV include intimidation, the psychosocial environment, and the nature of client care. If the perpetrators tell the victims that if they denounce them, they will be killed, the victims will probably choose not to report the violence. Some issues relating to the quality of the client care obtained by victims from the people dealing with IPV, as well as the way reported cases are followed up, are said to be factors that discourage IPV reporting. The first victims of IPV are the children, the collateral victims, followed by the women and then the men.

Participants proposed a number of measures aimed at preventing IPV: fighting against poverty, educating and sensitizing family members about their responsibilities and community leaders about laws and human rights, involving the churches in the fight against IPV by fostering mutual respect between family members, training and educating people about gender equality and IPV, increasing the access of people to the helping services and reducing the amount of travel required, implementing a law both discouraging and protecting free unions, creating a specific institution dedicated to IPV issues, engaging in premarital education, ensuring adequate follow-up of reported cases, and better supporting victims.

The criminal penalties for IPV should be strengthened and fully enforced in order to set an example that will inhibit other potential perpetrators. 
International Journal of Child, Youth and Family Studies (2017) 9(3): 68-99

\section{References}

Abramsky,T. Watts, C. H., Garcia-Moreno, C., Devries, K., Kiss, L., Ellsberg, M., ... Heise, L. (2011). What factors are associated with recent intimate partner violence? Findings from the WHO multi-county study on women's health and intimate partner violence. BMC Public Health, 11, 109. doi:10.1186/1471-2458-11-109

American Psychiatric Association. (2013). The Diagnostic and Statistical Manual of Mental Disorders. Fifth Edition. DSM-5. Washington, DC: Author.

Baribeau, C. (2009). Analyse des entretiens de groupe [Analysis of group interviews]. Recherches qualitatives, 28(1), 133-148.

Bélanger, C., Mathieu, C., \& Brisebois, H. (2013). Perception of partner abuse and its impact on marital violence from both spouses. Scientific Research, 4(11), 858-863. doi: $10.4236 /$ psych.2013.411123

Bragg, H. L. (2003). Child protection in families experiencing intimate partner violence. Washington, DC: U.S. Department of Health and Human Services, Administration for Children and Families.

Bowman, C. G. (2003). Theories of domestic violence in the African context. Cornell Law Faculty Publications, Paper 131. Retrieved from http://scholarship.law.cornell.edu/cgi/viewcontent.cgi?article $=1130 \&$ context=facpub

Centers for Disease Control and Prevention. (2015). Injury prevention \& control: Division of violence prevention, intimate partner violence. Atlanta, GA: Author. Retrieved from http://www.cdc.gov/violenceprevention/intimatepartnerviolence/

Duchesne, S., \& Haegel, F. (2005). L'entretien collectif [The collective interview]. Paris, France: Armand Colin.

Futures Without Violence. (2012). The facts on health care and domestic violence. Retrieved from http://www.futureswithoutviolence.org/userfiles/file/HealthCare/HealthCare.pdf

Ganley, A. L., \& Schechter, S. (1996). Intimate partner violence: A national curriculum for children's protective services. San Francisco, CA: Family Violence Prevention Fund.

García-Moreno, C., Pallitto, C., Devries, K., Stöckl, H., Watts, C., \& Abrahams, N. (2013). Global and regional estimates of violence against women: Prevalence and health effects of intimate partner violence and non-partner sexual violence. Geneva, Switzerland: World Health Organization. Retrieved from http://apps.who.int/iris/bitstream/10665/85239/1/9789241564625_eng.pdf 
International Journal of Child, Youth and Family Studies (2017) 9(3): 68-99

IGIHE. (2017 February 6). Domestic Violence: 64 killed, 10 suicides in 2016. IGIHE Network. Retrieved from http://en.igihe.com/news/domestic-violence-64-killed-10-suicides-in$\underline{2016 . h t m l}$

Kayibanda, J. F.; Bitera, R., \& Alary, M. (2012). Violence toward women, men's sexual risk factors, and hiv infection among women: Findings from a National Household Survey in Rwanda. Journal of Acquired Immune Deficiency Syndrome, 59(3), 300-307. doi:10.1097/QAI.0b013e31823dc634

Krug, E. G., Dahlberg, L. L., Mercy, J. A., Zwi, A. B., \& Lozano, R. (Eds.). (2002). World report on violence and health. Geneva, Switzerland: World Health Organization. Retrieved from http://whqlibdoc.who.int/publications/2002/9241545615_eng.pdf?ua=1

L'Écuyer, R. (1989). L'analyse développementale du contenu [The developmental analysis of content]. Revu de l'Association pour la Recherche Qualitative, 1, 51-80.

L'Écuyer, R. (1990). Méthodologie de l'analyse développementale de contenu: Méthode GPS et concept de soi [Methodology of the developmental analysis of content: Method of GPS and self-concept]. Sillery, QC: Presses de l'Université du Québec.

Miles, M. B., \& Huberman, A. M. (1994). Qualitative data analysis: An expanded sourcebook (2nd ed.). Newbury Park, CA: Sage.

Ministry of Gender and Family Promotion [MIGEPROF].(2005). National policy for family promotion. Kigali, Rwanda: Author. Retrieved from http://www.migeprof.gov.rw/fileadmin/_migrated/content_uploads/NATIONAL_POLICY FOR_FAMILY_PROMOTION-2.pdf

Ministry of Gender and Family Promotion [MIGEPROF]. (2011a). National policy against gender-based violence. Kigali, Rwanda: Author. Retrieved from http://www.migeprof.gov.rw/fileadmin/_migrated/content_uploads/GBV_Policy-2_1_.pdf

Ministry of Gender and Family Promotion [MIGEPROF]. (2011b). National strategic plan for fighting against gender-based violence 2011-2016. Kigali, Rwanda: Author. Retrieved from http://www.migeprof.gov.rw/fileadmin/_migrated/content_uploads/GBV_Policy_Strategic $\underline{\text { Plan-2.pdf }}$

Molinié, W. (2016, June 29). Violences conjugales: 122 femmes mortes sous les coups de leur compagnon en 2015 [Domestic violence: 122 women killed by their companion in 2015]. La Chaîne Info. Retrieved from http://www.lci.fr/faits-divers/violences-conjugales-122femmes-mortes-sous-les-coups-de-leur-compagnon-en-2015-1511813.html 
International Journal of Child, Youth and Family Studies (2017) 9(3): 68-99

Mukashema, I., \& Sapsford, R. (2013). Marital conflicts in Rwanda: Points of view of Rwandan psycho-socio-medical professionals. Procedia - Social and Behavioral Sciences, 82(3), 149-168. doi:10.1016/j.sbspro.2013.06.239

National Institute of Statistics of Rwanda, Ministry of Health, and ICF International. (2012). Rwanda Demographic and Health Survey 2010 [Final report]. Calverton, MD: Authors. Retrieved from https://dhsprogram.com/pubs/pdf/FR259/FR259.pdf

Ntaganira,J., Muula, A., Masaisa, F., Dusabeyezu, F., Siziya, S., \& Rudatsikira, E. (2008). Intimate partner violence among pregnant women in Rwanda. BMC Women's Health, 8, 17. Retrieved from http://www.biomedcentral.com/1472-6874/8/17

Nybergh, L., Taft, C., \& Krantz ,G. (2012). Psychometric properties of the WHO Violence Against Women instrument in a male population-based sample in Sweden. BMJ Open, 2(6), e002055. doi:10.1136/bmjopen-2012-002055

Picon, M. G., Rankin, K., Ludwig, J., Sabet, S. M., Delaney, A., \& Holst, A. (2017). Intimate partner violence prevention: An evidence gap map [3ie Evidence Gap Map Report 8]. International Initiative for Impact Evaluation (3ie). Retrieved from http://www.3ieimpact.org/media/filer_public/2017/06/30/egm8-ipv.pdf

Republic of Rwanda. (1999). Law to supplement book one of the civil code and to institute part five regarding matrimonial regimes, liberalities and successions. Official gazette J.O. $n^{\circ} 22$ of 1999. Retrieved from http://www.migeprof.gov.rw/fileadmin/_migrated/content_uploads/MATRIMONIAL_REG IMES_LIBERALITIES_AND_SUCCESSIONS-2.pdf

Republic of Rwanda. (2003). Constitution of Rwanda. Retrieved from http://www.rwandahope.com/constitution.pdf

Republic of Rwanda (2005). Organic Law n ${ }^{\circ}$ 08/2005 of 14/07/2005 determining the use and management of land in Rwanda. Official Gazette of the Republic of Rwanda. Retrieved from http://admin.theiguides.org/Media/Documents/organic land law.pdf

Republic of Rwanda. (2008). Law n ${ }^{\circ 59 / 2008}$ of 10/09/2008 on prevention and punishment of gender- based violence. Official Gazette of the Republic of Rwanda. Retrieved from http://gmo.gov.rw/fileadmin/user_upload/Laws/Law_No592008 on_the_Prevention_and_Punishment_of_Gender-Based_Violence.pdf

Republic of Rwanda. (2012). Law $N^{\circ} 54 / 2011$ relating to the rights and the protection of the child. Official Gazette $n^{\circ} 26$ of 25/06/2012. Retrieved from http://gmo.gov.rw/index.php?id=22 
International Journal of Child, Youth and Family Studies (2017) 9(3): 68-99

Republic of Rwanda. (2016). Law No32/2016 of 28/08/2016 governing persons and family. Official Gazette n'37 of 12/09/2016.

Rubanzana, W., Ntaganira, J., Freeman, M. D., \& Hedt-Gauthier, B. L. (2015). Risk factors for homicide victimization in post-genocide Rwanda: A population -based case- control study. BMC Public Health. Retrieved from http://www.biomedcentral.com/1471-2458/15/809

Rubin, H. J., \& Rubin, I. S. (1995). Qualitative interviewing: The art of hearing data. Thousands Oak, CA: Sage.

Rubin, H. J., \& Rubin, I. S. (2005). Qualitative interviewing : The art of hearing data (2nd ed.). Thousand Oaks, CA: Sage.

Schechter, S. (2000). New challenges for the battered women's movement: Building collaboration and improving public policy [On-line]. Retrieved from https://vawnet.org/sites/default/files/materials/files/2016-09/BCS1_col.pdf

Shipway, L. (2004). Intimate partner violence: A handbook for health professionals. London, UK: Routledge.

Sinha, M. (2012). Family violence in Canada: A statistical profile, 2010. Ottawa, ON: Statistics Canada, Canadian Centre for Justice Statistics.

Sinha, M. (2013). Family violence in Canada: A statistical profile, 2011. Ottawa, ON: Statistics Canada,Canadian Centre for Justice Statistics.

Slegh, H., \& Kimonyo, A. (2010). Masculinity and gender based violence in Rwanda: Experiences and perceptions of men and women. Kigali, Rwanda: Rwanda Men's Resource Centre. Retrieved from http://menengage.org/resources/masculinity-gender-based-violencerwanda-experiences-perceptions-men-women/

Thomson, D. R., Bah, A. B., Rubanzana, W. G., \& Mutesa, L. (2015). Correlates of intimate partner violence against women during a time of rapid social transition in Rwanda: Analysis of the 2005 and 2010 demographic and health surveys. BMC Women's Health, 15, 96. doi:10.1186/s12905-015-0257-3

United Nations Office on Drugs and Crime. (2013). The many faces of homicide. In United Nations Office on Drugs and Crime, Global study on homicide 2013: Trends, contexts, data (pp. 49-57). Vienna, Austria: Author. Retrieved from https://www.unodc.org/documents/gsh/pdfs/Chapter_2-2.pdf

Umubyeyi, A., Mogren, I., Ntaganira, J., \& Krantz, G. (2014). Intimate partner violence and its contribution to mental disorders in men and women in the post genocide Rwanda: Findings from a population based study. BMC Psychiatry, 14, 315. doi:10.1186/s 12888-014-0315-7 
International Journal of Child, Youth and Family Studies (2017) 9(3): 68-99

Umubyeyi, A., Persson, M., Mogren, I., \& Krantz , G. (2016). Gender inequality prevents abused women from seeking care despite protection given in gender-based violence legislation: A qualitative study from Rwanda. PLoS ONE. doi:10.1371/journal.pone.0154540

Verduin, F., Engelhard, E. A. N., Rutayisire, T., Stronks, K., \& Scholte, W. F. (2012). Intimate partner violence in Rwanda: The mental health of victims and perpetrators. Journal of Interpersonal Violence, 28, 1839-1858. doi:10.1177/0886260512469106

Were, E., Curran, K., Delany-Moretlwe, S., Nakku-Joloba, E., Mugo, N. R., Kiarie, J., ... Baeten, J. M. (2011). A prospective study of frequency and correlates of intimate partner violence among African heterosexual HIV serodiscordant couples. AIDS, 25(16), 20092018. doi:10.1097/QAD.0b013e32834b005d 